\title{
FACES DA CRISE CONTEMPORÂNEA: UMA LEITURA DA OBRA ESTADO DE CRISE DE ZYGMUNT BAUMAN E CARLO BORDONI
}

BAUMAN, Zygmunt; BORDONI, Carlo. Estado de crise. Tradução de Renato Aguiar. Rio de Janeiro: Zahar, 2016. 191p.

Estado de crise é uma obra de fundamental importância para a compreensão da crise contemporânea. Com bastante lucidez e profunda provocação à reflexão, o sociólogo polonês Zygmunt Bauman e o sociólogo italiano Carlo Bordoni estabelecem um diálogo comprometido com o esclarecimento e a crítica dos fundamentos da crise atual, mundialmente vivenciada, por meio da análise do cenário político, econômico e social global. Nesse sentido, não se trata de uma obra que traga soluções definidas para a atual situação emergencial; pelo contrário, o ceticismo dos autores quanto a um futuro não tão distante faz com que o leitor, apesar da clareza em relação aos fundamentos da crise, experimente certa aflição quanto ao que está por vir.

Marcada, portanto, pela crítica fundamental e objetividade da discussão, essa obra está dividida em três partes estruturantes nas quais se desenvolvem pequenos capítulos, a saber: "Crise do Estado", "Modernidade em crise" e, por fim, "Democracia em crise". Na primeira parte, os autores propõem a discussão acerca do conceito de crise e uma análise das crises que afetam o Estado Moderno, institucionalizando-se nele. Já a segunda parte apresenta a crise da modernidade como consequência do descumprimento de suas promessas, ensejando a possibilidade de uma modernidade tardia marcada pela liquidez. Por fim, a terceira parte traz uma profunda discussão quanto ao atual modelo democrático, evidenciando-se suas incongruências, insuficiências, contradições e oscilações. Portanto, trata-se de um livro que,

\footnotetext{
* Advogada. Pós-Doutora em Direito do Trabalho pela Universidad Castilla La-Mancha. Doutora em Direito do Trabalho e da Seguridade Social pela Universidade de São Paulo. Mestre em Direito do Trabalho pela Pontifícia Universidade Católica de Minas Gerais. Professora do Programa de Pós Graduação Stricto Sensu e da Graduação da Pontifícia Universidade Católica de Minas Gerais. E-mail: cecimax@ @ucminas.br.

** Advogado. Licenciado em Filosofia pelo Instituto Santo Tomás de Aquino e bacharel em Direito pela Escola Superior Dom Helder Câmara. Mestrando em Direito Privado pela Pontifícia Universidade Católica de Minas Gerais. Bolsista CAPES. E-mail: gusfilgueiras@gmail.com.
} 
apesar de denotar não ter um objetivo de raciocínio retilíneo quanto à disposição dos capítulos e ideias expostas, visa concentrar argumentos importantes quanto aos temas em debate, possibilitando o acesso a uma análise conjuntural objetiva, sem que, com isso, a qualidade dela fique prejudicada.

\section{CRISE DE ESTADO}

A primeira parte da obra se inicia com a definição dos autores do conceito de crise. Para tanto, buscam nas ciências médicas tal definição. A crise, nesse contexto, se refere ao momento no qual a equipe médica se encontra diante do paciente gravemente enfermo, faz o diagnóstico e deve decidir qual o tratamento eficaz para que este recobre a saúde. Trata-se, portanto, de um momento fundamental, quando a decisão daí advinda será determinante para a manutenção da vida ou óbito do enfermo. Dessa forma, na crise contemporânea, aquilo que deveria ser transitório, a fim de se iniciar o tratamento eficaz, tem-se arrastado de forma indeterminada. Trata-se de uma crise sem precedentes e da qual não se pode inferir (ao menos por enquanto) seu estágio final.

Nesse sentido, as reflexões dos autores centram na função do Estado-nação Moderno e sua falência enquanto agente soberano oriunda, principalmente, das grandes crises políticoeconômicas recentes. Tais crises e a incapacidade dos Estados em darem soluções definitivas a elas, a fim de preservar seu caráter provisório, faz com que o Estado ingresse em um profundo declínio do seu poder de agência, tenha reduzida sua potencialidade de ação, supervalorize a esfera econômica, resultando no domínio do Capital e, assim, fomente o crescimento de entidades supraestatais de caráter decisório, levando à relativização de sua soberania.

Nesse cenário, a crise de Estado repousa no divórcio entre o poder e a política, ocasionada pela nova forma de organização do Capital no mundo, onde se retiram do Estado os marcos regulatórios e limitadores da economia. No entanto, para que se entenda tal divórcio e suas consequências, é importante conceituar poder e política.

Conforme os autores, por poder entende-se "[...] a capacidade de levar as coisas a cabo" (p. 32). Já a política é "[...] a habilidade de decidir que coisas são necessárias e devem ser feitas [...]" (p. 32). Assim, quando o Estado perde essas duas dimensões, ingressa em verdadeira crise de agência. Sua capacidade de regulamentação e efetiva ação está extremamente prejudicada, tendo em vista que a atual economia prescinde de bases territoriais 
e fronteiriças de normatizações estatais. Existem entidades supraestatais globais que, agora, exercem o poder, relegando ao Estado apenas o exercício da política. Dessa forma, o conceito moderno de soberania está extremamente fragilizado, denotando um esfacelamento do Estado hobbesiano e gerando um "estatismo sem Estado" (p. 22). O Estado perdeu a capacidade de lidar com as questões globais que lhe afetam em seu âmbito, não conseguindo responder à crise atual como o fez em 1929 (época em que ainda reunia as duas dimensões de poder e política, e as pessoas sabiam a quem recorrer em situação semelhante). Portanto, os autores concordam que, apesar dos problemas serem globais, os Estados possuem apenas poderes regionais, simplesmente pelo âmbito político, para enfrentá-los. Apequenaram-se.

Além disso, também como consequência dessa crise de Estado, se enfraquece o comum sentimento de nação. O descaso com os indivíduos que formam o seu povo e seu crescente abandono faz com que cresça o individualismo aliado a governos neoliberais, aptos ao cumprimento de uma agenda econômica previamente estabelecida por quem exerce o poder.

\section{MODERNIDADE EM CRISE}

A segunda parte da obra é marcada por relevante discussão entre os autores quanto ao desenvolvimento histórico da modernidade e suas crises. Bordoni (2016), fazendo uso de escrita ousada, sustenta que a modernidade descumpriu suas promessas em garantir segurança e liberdade, em perfeita manutenção da ordem, do progresso e da propriedade privada, enaltecendo a autonomia conquistada pelo humano em relação aos períodos históricos anteriores. Assim, para Bordoni (2016), a modernidade findou-se, iniciando o seu período póstumo, ou seja, a pós-modernidade.

Bauman (2016), no entanto, é reticente em aceitar o termo "promessas" para designar os princípios iniciais, estratégias da modernidade para o cumprimento de suas promessas, tendo em vista estas ainda se afirmarem. Também não entende que o mundo contemporâneo vivencia um período póstumo à modernidade. Para o sociólogo polonês, não há que se falar em pós-modernidade, mas na sua liquidez; ou seja, não existe um rompimento com a agenda moderna, somente a superfluidez de mudanças das sociedades que estão sob o prisma da modernidade. Esse estado de liquidez, que estabelece o império de um eterno presente avesso à memória, concretiza, portanto, a crise da modernidade. 


\section{DEMOCRACIA EM CRISE}

A liquidez moderna atrelada à crise do Estado, tendo como suporte o esfacelamento dos direitos sociais, o individualismo exacerbado, o consumismo, entre outros, faz com que surja uma grande desconfiança na capacidade do Estado em autorregular-se e prover o mínimo necessário à vida digna. Dessa desconfiança surge também a crise em relação ao modelo de democracia contemporânea, ocasionando um sentimento de aversão dos indivíduos em relação à política e suas instituições.

Os autores constatam que essa aversão é fruto da cisão ocorrida entre os cidadãos e a política, por meio da perda progressiva da confiança no Estado, devido ao fato deste não ser suficiente para garantir seus compromissos sociais e, tampouco, a si próprio pelo divórcio entre poder e política. A esse fenômeno, os sociólogos dão o nome de "pós-democracia", inspirando-se no conceito de Colin Crouch. Ela difere-se da "desdemocratização" de Charles Tilly, que se refere ao processo de governos antidemocráticos de retirarem do Estado seu compromisso social.

Importante, por fim, demonstrar que, para os autores, a sociedade contemporânea carece de um Estado capaz de intervir de forma eficaz nas crises que o atingem. Tal carência leva ao descrédito das suas instituições. Assim, esse modelo democrático no qual o Estado se estabelece, ao que parece, está fadado ao fracasso pela cisão entre cidadãos e política. Nesse sentido, conforme Bauman (2016), a crise da democracia é a mais séria, pois coloca em falência os instrumentos de ação coletiva para a resistência às demais crises. Fica, por fim, o alerta de Bordoni (2016): o fim da democracia representativa gera o término do mundo organizado na forma como o conhecemos. Portanto, decretá-lo seria uma espécie de "tiro no escuro" do qual não sabemos as consequências que possam vir.

\section{CONCLUSÃO}

A liquidez da modernidade e suas constantes mudanças geram grandes e rápidas transformações na sociedade, exigindo de seu crítico uma análise profunda dos seus pilares e contradições, a fim de tentar estabelecer o nexo das crises que solapam o mundo contemporâneo. Nesse sentido, a obra aqui apresentada se torna um referencial bibliográfico para pensar a crise que envolve o Estado-nação e de seu referencial, ocasionando a desconfiança em suas instituições, de seu papel no mundo, tal quais os ditames de sua origem 
moderna. Na verdade, os sociólogos denunciam a flexibilização contemporânea da noção de soberania em prol do domínio do Capital em sua forma de organização neoliberal globalizada, também em crise.

Pelo divórcio entre poder e política, sendo o Estado mero gestor da agenda que lhe é imposta por entidades supraestatais que exercem o poder, abandona seus compromissos sociais e passa a ser viabilizador do poder do Capital. Nesse aspecto, é possível compreender o golpe de 2016, ainda em curso, e as reformas legislativas pelas quais o Brasil vem passando, onde a retirada abrupta de direitos sociais historicamente conquistados, ensejando o aumento da pobreza, da violência e dos demais problemas sociais, concretiza o projeto do Capital na obtenção do lucro a qualquer custo, na manutenção de privilégios e da desigualdade social.

Assim, de fato, imersos em uma crise sem precedentes e impossibilitados de visualizar seu término, resta-nos a resistência, para que a crise da democracia e do Estado não nos relegue a condições de deploração humana irreversíveis. Para tanto, entender o período que vivemos, a fim de cunhar práxis emancipatórias, é obrigação de todos nós, garantindo-se que uma sociedade com melhor distribuição de renda, igualdade e justiça social não se configure em mera dimensão utópica, mas em realidade concreta a partir da compreensão de que todos e todas possuem igual direito de existir neste mundo plural e terem sua dignidade humana respeitada.

\section{REFERÊNCIA}

FEITOSA, Rodolfo Rodrigo Santos. Crise, uma condição intrínseca à modernidade: realidades e horizontes da sociedade contemporânea. Revista Sociedade e Estado, Brasília, v. 32, n. 2, p. 541-546, mai./ago. 2017. 